\title{
Tilapia Fish Skin: a new biological graft in gynecology
}

Vaginal agenesis is a rare mal-formation of the lower female genital tract, with a prevalence of 1 in 5000 female newborns. Mayer-Rokitansky-Kuster-Hauser (MRKH) syndrome represents $90 \%$ of all causes and is caused by partial or complete aplasia of the Mullerian ducts. The majority of these women have complete uterine agenesis. Primary amenorrhea is the first clinical sign, in patients with 46 XX karyotype, functioning ovaries and normal external genitalia. ${ }^{1}$

Creating a satisfactory neovagine when sexual activity is desired is primarily the goal of treatment. This ideal vaginal reconstruction should provide a long-lasting, functional passage for sexual intercourse that does not need maintenance with dilators or lubrication for sexual activity. At present, however, no standard treatment exists. Progressive dilatation is recommended by the American College of Obstetricians and Gynecologists as the first choice for creation of a neovagina, ${ }^{2}$ but this requires highly motivated patients and has a considerable failure rate. ${ }^{3}$ Surgical treatment usually shares a common step of tissue dissection between the urinary tract and the rectum.

There are many surgical techniques for creating a neovagina: using olive-shaped plastic forms combined with traction devices (Vecchietti technique), Hegar dilatators or specially constructed bicycle seats for dilatation; bowel transplants; labial, thigh, or subcutaneous abdominal flaps; and insertion of an inlay split-thickness skin graft, or peritoneal graft. However, consensus has not been reached concerning the best therapeutic approach. Additionally, in the surgical treatment of neovaginoplasty is necessary not only to open the canal, but also to cover it with some material that mimicked the vaginal mucosa, functioning as a scaffold. Several biomaterials have relied on tissues, such us peritoneum, ${ }^{4}$ various segments of the colon, ${ }^{5}$ amnion ${ }^{6}$ or skin grafts, ${ }^{7}$ which are often associated with complications due to prolonged, complex surgery and the inherent physiological differences of these substrates. Neovaginoplasty with autologous skin graft is one of the most used techniques in recent reviews. It had success rates, but leaves stigmatizing scars. In fact, the large abdominal or inguinal incision for the reconstruction procedure was an important drawback.

The Child and Adolescent Health Care Unit from Maternidade Escola Assis Cheteaubriand (MEAC) - Universidade Federal do Ceará (UFC) in association with The NPDM (Nucleus of Research and Development of Medicines - Universidade Federal do Ceará) seek an alternative to skin grafting for neovaginoplasty with an easily accessible material in relation to cost. Previously, Dr. Manoel Odorico de Moraes Filho and Edmar Maciel Lima Júnior had excellent results with use the skin of Nile tilapia in burn patients in Institute Dr José Frota (Center of Burns) after Radiosterilization, the glycerol protocol and skin conditioning in the NPDM laboratories. Tilapia skin has also been suggested as a possible biological material due its collagenous, histological and mechanical similarity to human skin and to other available biomaterials. ${ }^{8,9}$ For the scaffold manufacturing, bioactive natural organic material such as fish collagen originated from aquatics products have been widely investigated because the severe bovine, avian and swine inflectious problems (zoonosis). Thereafter, Dr. Zenilda Vieira Bruno and Dr. Leonardo Bezerra from MEAC-UFC proposed to study this material utilization as well for the formation of a scaffold for proliferation of a new vaginal epithelium. The idea was replacing the patient's own skin, as has been traditionally used for more than twenty years.

The surgical treatment of neovaginoplasty is a minimally invasive procedure. We evaluated the tilapia skin use as a scaffold in neovaginoplasty (Figure) in one patient that had Müllerian agenesis (agenesis of the proximal two-thirds of the vagina, with normal external genitalia, with karyotype 46, XX and female phenotype). The patients had a surgical indication and wished to undergo a neovaginoplasty. She signed the Informed Consent Form to perform the procedure and was submitted to surgery in 13/09/2017. The surgery ran without intercurrences. The patient evolved well after leaving the hospital and maintained her outpatient followup at 30,60, 90 and 180 days after surgery. She used the soft silicone mold continuously ( 24 hours a day) for 3 consecutive months and then went on to use it only at night while sleeping. In the 90 -day study, a vagina with a good length $(>10 \mathrm{~cm}$ ) and half of its extension (right and posterior lateral wall) was observed vaginal tissue healed, smooth and without areas of granulomas.

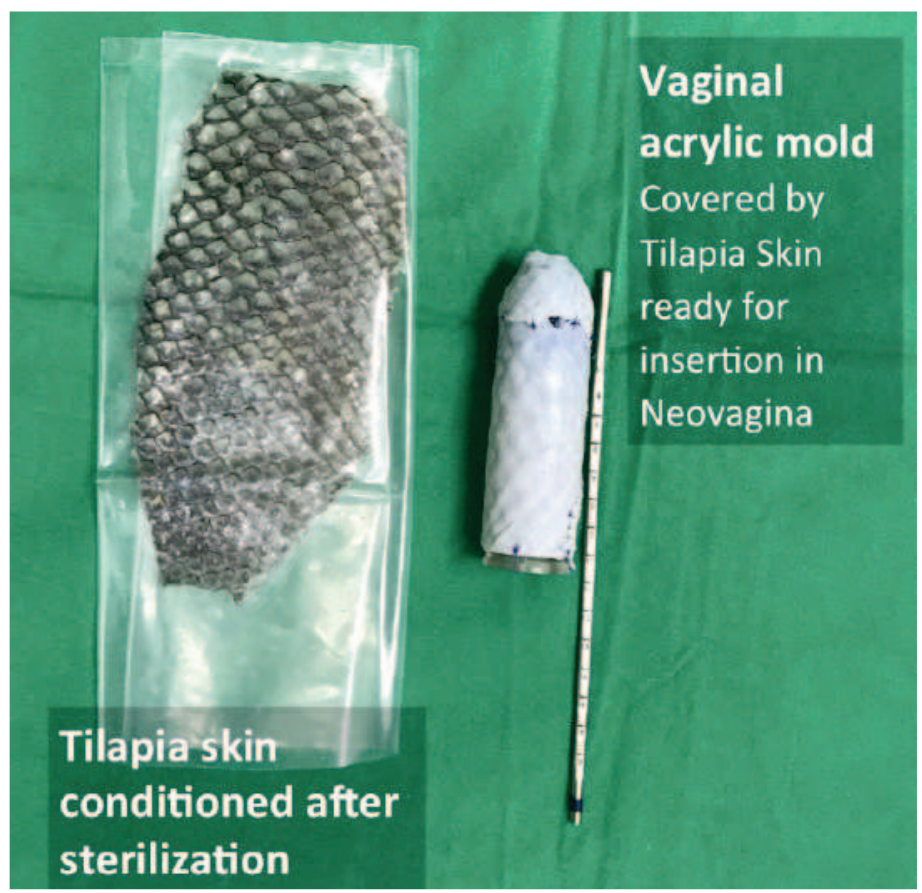


Evaluation of the postoperative results after intervals of 2-6 months revealed a well-formed neovagina in the patient, with a length of $10 \mathrm{~cm}$ and a two-finger width. The patient was released for sexual intercourse. There was not mucosal prolapse; there were no surgical, urinary, or gastrointestinal infections or complications. Follow-up will continue.

Tissue bioengineering is a global concern in development. Different biomaterials are studied and created in regenerative medicine for to be safe, effective and with low cost. The basic principle of tissue engineering is that cells, genes, and proteins are delivered via a degradable material, termed as scaffold, to regenerate tissue. ${ }^{10}$

Bioactive materials for biomedical uses has been traditionally obtained from mammalian sources (primarily bovine or porcine skin), but mammalian tissues have recently been suspected as posing a large risk of pathogens such as the transmission of infectious diseases to humans. Severe inflectional problems (zoonosis); bovine spongiform encephalopathy, avian and swine influenzas, and tooth-and-mouth disease in bovine, pig, and buffalo occur all over the world still now. An alternative material to mammalian collagen is, therefore, urgently needed in the medical field, especially in the tissue engineering research field. Collagen from aquatic animals like fishes and mollusks is considered to be a possible alternative to mammalian collagen because of its lower risk. Fish skin and scales are abundant and can be obtained from food industries, supporting availability of fish collagen in abundance..$^{8,11-13}$

Tilapia skin had shown its biological potential as covers for the burn wound due to its collagenous, histological and mechanical similarity to human skin and to other available biomaterials. ${ }^{14-16}$ Vaginal agenesis has an important impact in self-estim and quality of life in women. Because of the potential morbidity associated with harvesting autologous women skin in neovaginoplasty, the use of allograft tissue can be a desirable alternative. The treatment has to be done in the perspective to provide to these patient an effective, safe, comfortable and low morbidy procedure. Allograft mammalian extra celular matrix (ECM) materials have also been reported to be more cost-effective than autologous, in others countries like USA, but have a potential risk of prion or viral transmission despite extensive preparation to avoid this and thus reduce antigenicity. ${ }^{17,18}$

Tilapia fish skin presents dense fibrous connective tissue layer, mainly, collagen type I. As such, it can constitute a possible graft material similar to other ECM xenografts which work as anti-bacterial barrier, reduce wound fluid and protein losses and contribute to ideal conditions for would healing processes to progress satisfactorily. Fish type I collagen have been considered as an effective material for a biodegradable scaffold or spacer replicating the natural extracellular matrix, which serves to spatially organize cells, providing them with environmental signals and directing site-specific cellular regulation. ${ }^{19,20}$ Additionally, In recent publication of our research group, we found that chemical sterilization as well as radiosterilization at the dosages of $25 \mathrm{kGy}$ and $30 \mathrm{kGy}$ are effective in preparing Nile Tilapia skin for usage as a biological dressing, and these methods do not alter their microscopical nor their tensiometric properties. ${ }^{21}$

Another aspect to be considered is the fact that most of the biomaterials available in our country, and all developed world, as wound dressings are imported and come at very high cost. Dornellas et $\mathrm{al}^{22}$ had evaluate the histological, anatomical and functional results of the McIndoe procedure, as modified by the application of oxidized cellulose (SurgicelTM) in women with vaginal agenesis in our country. The procedure described had offers patients a functional vagina by means of a simple but, unfortunately, not low-cost procedure.

Therefore, tilapia collagen is believed to be a powerful candidate for use in making a clinical scaffold as an alternative to bovine and porcine ECM Allograft and oxidized cellulose. We report here the benefits and advantages associated with the use of tilapia fish Skin to create a satisfactory neovagina in MRKH. This technique may be considered, based on our results, an effective option for the surgical treatment of women with vaginal agenesis without a functional uterus. Originally, Tilapia skin is possible usage as a biological dressing material would be of one with practically unlimited availability, low cost and excellent quality. The implementation of this novel biomaterial derived from the Nile Tilapia would produce great technological advancement with significant financial and social impact for the health system.

\section{REFERENCES}

1. Morcel K, Camborieux L, Guerrier D. Mayer-Rokitansky-Kuester syndrome: clinical description and genetics. J Gynecol Obstet Biol Reprod. 2008;37:539-46.

2. Commitee on Adolescent Health Care. American College of Obstetrics and Gynecology. ACOG commitee opinion no. 335: vaginal agenesis: diagnosis, management, and routine care. Obstet Gynecol. 2006;108:1605.

3. Fedele L, Frontino G, Restelli E. Creation of a neovagina by Davidov's laparoscopic moified technique in patients with Rokitansky syndrome. Am J Obstet Gynecol. 2010;202:33.e1-e6.

4. Marques HS, Santos FL, Costa PV. Creation of a neovagina in patients with Rokitansky syndrome using peritoneum from the pouch of Douglas: an analysis of 48 cases. Fertil Steril. 2008;90:827-32. 
5. Karateke A, Haliloglu B, Parlak O, Coksuer H. Intestinal vaginoplasty: seven years'experience of a tertiary center. Fertil Steril. 2010;94:2312-5.

6. Fotopoulou C, Sehouli J, Gehrmann N, Lichtenegger W. Functional and anatomic results of amnion vaginoplasty in young women with Mayer-Rokitansky- Kuster-Hauser syndrome. Fertil Steril. 2010;94:317-23.

7. McIndoe AH, Banister JB. An operation for the cure of congenital absence of the vagina. J Obstet Gynaecol Br Emp. 1938;45:490-4.

8. Dillow AK, Lowman AM. Biomimetic materials and design: biointerfacial strategies, tissue engineering, and targeted drug delivery. New York: Mercel Dekker; 2002.

9. Yang S, Leong KF, Du Z, Chua CK. The design of scaffolds for use in tissue engineering. Part I. Tissue Eng. 2001;7(6):679-89.

10. Langer R, Cima LG, Tamada JA, Wintermantel E. Future directions in biomaterials. Biomaterials. 1990;11:738-45.

11. Badylak SF. Xenogeneic extracellular matrix as a scaffold for tissue reconstruction. Transpl Immunol. 2004;12:367-77.

12. Yang AF, Leong KF, Du ZH, Chua CK. The design of scaffolds for use in tissue engineering. Part 1. Traditional factors. Tissue Eng. 2001;7:679-89.

13. Sugiura H, Yunoki S, Kondo E, Ikoma T, Tanaka J, Yasuda K. In vivo biological responses and bioresorption of tilapia scale collagen as a potential biomaterial. J Biomater Sci Polym Ed. 2009;20(10):1353-68.

14. Norbury W, Herndon DN, Tanksley J, Jeschke MG, Finnerty CC. Infection in Burns. Surg Infect (Larchmt). 2016;17(2):250-5.

15. Guo ZQ, Qiu L, Gao Y, Li JH, Zhang XH, Yang XL, et al. Use of porcine acellular dermal matrix following early dermabrasion reduces length of stay in extensive deep dermal burns. Burns. 2016;42(3):598-604.

16. Ramakrishnan KM, Babu M, Mathivanan VJ, Shankar J. Advantages of collagen based biological dressings in the management of superficial and superficial partial thickness burns in children. Ann Burns Fire Disasters. 2013;26(2):98-104

17. Anderson JM, Rodriguez A, Chang DT. Foreign body reaction to biomaterials. Semin Immunol. 2008;20:86-100.

18. Luttikhuizen DT, Harmsen MC, Van Luyn MJ. Cellular and molecular dynamics in the foreign body reaction. Tissue Eng. 2006;12:1955-70.

19. Wang JH, Hung CH, Young TH. Proliferation and differentiation of neural stem cells on lysine-alanine sequential polymer substrates. Biomaterials. 2006;27(18):3441-50.

20. Hayashi Y, Yamada S, Ikeda T. Fish collagen and tissue repair. In: Kim SK. Marine cosmeceuticals: trends and prospects. Boca Raton (FL): CRC Press; 2011. p. 133-41.

21. Alves AP, Lima EM Júnior, Piccolo NS, de Miranda MJ, Lima Verde ME, Ferreira AE Júnior, et al. Study of tensiometric properties, microbiological and collagen content in nile tilapia skinsubmitted to different sterilization methods. Cell Tissue Bank. 2018:1-10.

22. Dornelas J, Jármy-Di Bella ZI, Heinke T, Kajikawa MM, Takano CC, Zucchi EV, Girão MJ. Vaginoplasty with oxidized cellulose: anatomical, functional and histological evaluation. Eur J Obstet Gynecol Reprod Biol. 2012;163(2):204-9.

Leonardo Robson Pinheiro Sobreira Bezerra ${ }^{1}$. Manoel Odorico de Moraes Filho². Zenilda Vieira Bruno ${ }^{1}$. Edmar Maciel Lima Júnior³ . Ana Paula Negreiros Nunes Alves ${ }^{4}$. Andreisa Paiva Monteiro Bilhar 5 . Maria Tereza Pinto Medeiros Dias ${ }^{6}$ Livia Cunha Rios 7.

1 Universidade Federal do Ceará (UFC), Departamento de Saúde Materno-Infantil. 2 Universidade Federal do Ceará (UFC), Departamento de Fisiologia e Farmacologia, Núcleo de Pesquisa e Desenvolvimento de Medicamentos (NPDM-UFC). 3 Instituto Dr José Frota. 4 Universidade Federal do Ceará (UFC), Departamento de Clínica Odontológica, Núcleo de Pesquisa e Desenvolvimento de Medicamentos (NPDM-UFC). 5 Serviço de Uroginecologia, Maternidade Escola Assis Chateaubriand (MEAC), Universidade Federal do Ceará (UFC). 6 Unidade de Cuidado à Saúde da Criança e do Adolescente, Maternidade Escola Assis Chateaubriand (MEAC). 7 Universidade Federal do Ceará (UFC).

\section{Como citar:}

Bezerra LR, Moraes MO Filho, Bruno ZV, Lima EM Júnior, Alves AP, Bilhar AP, et al. Tilapia Fish Skin: a new biological graft in gynecology. Rev Med UFC. 2018 abr-jun;58(2):6-8. 